\title{
Scotopic Visual Signaling in the Mouse Retina Is Modulated by High-Affinity Plasma Membrane Calcium Extrusion
}

\author{
Jacque L. Duncan, ${ }^{1}$ Haidong Yang, ${ }^{1}$ Thuy Doan, ${ }^{2}$ Robert S. Silverstein, ${ }^{4}$ Gabe J. Murphy, ${ }^{3,4}$ George Nune, ${ }^{1}$ Xiaorong Liu, ${ }^{1}$ \\ David Copenhagen, ${ }^{1,2}$ Bruce L. Tempel, ${ }^{4}$ Fred Rieke, ${ }^{3,4}$ and David Križaj ${ }^{1}$ \\ Departments of ${ }^{1}$ Ophthalmology and ${ }^{2}$ Physiology, University of California San Francisco School of Medicine, San Francisco, California 94143-0730, \\ ${ }^{3}$ Departments of Physiology and Biophysics and Howard Hughes Medical Institute, and ${ }^{4}$ Otolaryngology-Head and Neck Surgery and the Neurobiology and \\ Behavior Program, University of Washington School of Medicine, Seattle, Washington 98195
}

Transmission of visual signals at the first retinal synapse is associated with changes in calcium concentration in photoreceptors and bipolar cells. We investigated how loss of plasma membrane $\mathrm{Ca}^{2+}$ ATPase isoform 2 (PMCA2), the calcium transporter isoform with the highest affinity for $\mathrm{Ca}^{2+} /$ calmodulin, affects transmission of rod- and cone-mediated responses. PMCA2 expression in the neuroblast layer was observed soon after birth; in the adult, PMCA2 was expressed in inner segments and synaptic terminals of rod photoreceptors, in rod bipolar cells, and in most inner retinal neurons but was absent from cones. To determine the role of PMCA2 in retinal signaling, we compared morphology and light responses of retinas from control mice and deafwaddler $d f w^{2 J}$ mice, which lack functional PMCA2 protein. The cytoarchitecture of retinas from control and $d f w^{2 J}$ mice was indistinguishable at the light microscope level. Suction electrode recordings revealed no difference in the sensitivity or amplitude of outer segment light responses of control and $d f w^{2 J}$ rods. However, rod-mediated ERG b-wave responses in $d f w^{2 J}$ mice were $\sim 45 \%$ smaller and significantly slower than those of control mice. Furthermore, recordings from individual rod bipolar cells showed that the sensitivity of transmission at the rod output synapse was reduced by $\sim 50 \%$. No changes in the amplitude or timing of cone-mediated ERG responses were observed. These results suggest that PMCA2-mediated $\mathrm{Ca}^{2+}$ extrusion modulates the amplitude and timing of the high-sensitivity rod pathway to a much greater extent than that of the cone pathway.

Key words: photoreceptor; PMCA; deafwaddler; retina; ERG; slice

\section{Introduction}

The time course and amplitude of changes in presynaptic and postsynaptic $\left[\mathrm{Ca}^{2+}\right]_{\mathrm{i}}$ are key determinants of the kinetics of neuronal signaling (Barrett and Stevens, 1972; Felmy et al., 2003). For short, action potential-driven stimuli, the time course of the intracellular calcium concentration $\left[\mathrm{Ca}^{2+}\right]_{i}$ generally reflects the kinetics of $\mathrm{Ca}^{2+}$ influx via voltage-activated $\mathrm{Ca}^{2+}$ channels and intracellular buffering (Meinrenken et al., 2003). However, after high-frequency stimulation or during sustained $\mathrm{Ca}^{2+}$ influx at tonic synapses, release is governed by residual $\left[\mathrm{Ca}^{2+}\right]_{\mathrm{i}}$ and its time course is determined by the properties of presynaptic $\mathrm{Ca}^{2+}$ extrusion (Tank et al., 1995; Zhong et al., 2001).

\section{Received July 10, 2004; revised April 28, 2006; accepted April 30, 2006.}

This work was supported by National Institutes of Health Grants EY13870 (D.K.), EY00415 (J.L.D.), EY01869 (D.R.C.), EY01919 (H.Y.), EY11850 (F.R.), DC02739 (B.L.T.), and EY02162 (D.K., J.L.D., D.R.C.), That Man May See (J.L.D., H.Y., D.R.C., D.K.), a career development award from Research to Prevent Blindness (J.L.D.), a career development award from The Foundation Fighting Blindness (J.L.D.), the Bernard A. Newcomb Macular Degeneration Fund (J.L.D., G.N.), the Howard Hughes Medical Institute (G.J.M., F.R.), and an unrestricted grant from Research to Prevent Blindness to the University of California, San Francisco Department of Ophthalmology. D.K. is a recipient of the James S. Adams Scholar Award from Research to Prevent Blindness. We are grateful to Edwin Dumlao, Doug Yasumura, and Linda Robinson for technical assistance. We thank Dr. Laura Frishman for her comments on this manuscript.

Correspondence should be addressed to David Križaj, Department of Ophthalmology, Beckman Vision Center, Room K-131, University of California, San Francisco School of Medicine, 10 Koret Way, San Francisco, CA 94143-0730. E-mail: krizaj@phy.ucsf.edu.

DOI:10.1523/JNEUROSCI.5230-05.2006

Copyright $\odot 2006$ Society for Neuroscience $\quad$ 0270-6474/06/267201-11\$15.00/0
Plasma membrane $\mathrm{Ca}^{2+}$ extrusion is controlled by two transporter families: $\mathrm{Na}^{+} / \mathrm{Ca}^{2+}$ exchangers (NCXs) and plasma membrane $\mathrm{Ca}^{2+}$ ATPases (PMCAs). In general, PMCAs have $\sim 10$-fold higher affinity for $\mathrm{Ca}^{2+}$ than NCXs and therefore regulate baseline $\left[\mathrm{Ca}^{2+}\right]_{\mathrm{i}}$ and $\left[\mathrm{Ca}^{2+}\right]_{\mathrm{i}}$ kinetics during transient depolarizations (Blaustein et al., 1991; Wanaverbecq et al., 2003). The PMCA family consists of four isoforms, which are expressed in a cell type- and tissue-specific manner throughout the brain (Stahl et al., 1992; Stauffer et al., 1995). With exception of cochlear and vestibular structures, which are highly dependent on PMCA isoform 2 (PMCA2) (Street et al., 1998; Dodson and Charalabapoulou, 2001), the significance of these isoforms for neuronal function is mostly unknown.

PMCA2 has $\sim 10$ times higher affinity for $\mathrm{Ca}^{2+} /$ calmodulin than the other three PMCA isoforms (apparent $K_{\mathrm{m}}$ of 2-4 nM) (Hilfiker et al., 1994) and is the fastest $\mathrm{Ca}^{2+}$ pump activated in response to an increase in $\left[\mathrm{Ca}^{2+}\right]_{\mathrm{i}}$ (Caride et al., 2001; Brini et al., 2003). PMCA2 expression is especially prominent in the brain and in sensory tissues (Dumont et al., 2001; Križaj et al., 2002; Burette et al., 2003; Silverstein and Tempel, 2006), indicating that this isoform could play a significant role in sensory transmission. Defects in the ATP2B2 gene encoding PMCA isoform 2 produce severe neurological phenotypes (Kozel et al., 1998; Street et al., 1998; Takahashi and Kitamura, 1999; Shull, 2000). In the deafwaddler mouse mutant $d f w^{2 J}$, a 2 bp deletion in Atp2b2 produces a frame-shift mutation that causes a reduction in the Atp $2 b 2$ 
transcript and loss of PMCA2 protein (Street et al., 1998; McCullough and Tempel, 2004). Homozygous deafwaddler mice have severe abnormalities in the function of cochlear, vestibular, cerebellar, and sensory brainstem structures resulting in tremor, ataxia, hyperexcitability, and deafness (Noben-Trauth et al., 1997; Street et al., 1998; Konrad-Martin et al., 2001).

Given the prominent PMCA2 expression in retinal neurons (Križaj et al., 2002), its upregulation during retinal development (Rentería et al., 2005) and its key role in development and function of the cochlea and vestibular system (Street et al., 1998), which share a number of signaling elements with the retina (Zenisek et al., 2003; El-Amraoui and Petit, 2005), we hypothesized that PMCA2 modulates the establishment of retinal circuits in the developing retina as well as light responses at mature retinal synapses. To test this hypothesis, we analyzed retinal development and transmission of light-evoked signals in control and $d f w^{2 I}$ mice.

\section{Materials and Methods}

\section{Animals}

All studies were conducted in accordance with the Association for Research in Vision and Ophthalmology Statement for the Use of Animals in Ophthalmic and Vision Research and guidelines issued by the Society for Neuroscience. The care and use of animals presented in this study were approved by the Animal Care and Use Committees at the University of Washington and the University of California, San Francisco.

The Atp $2 b 2^{d f w 2 J}$ mouse strain (referred to here as $d f w^{2 J}$ ) arose spontaneously in CBy.A/J-fsn (a substrain of BALB/cByJ) at The Jackson Laboratory (Bar Harbor, ME) (Noben-Trauth et al., 1997). Obtained in 1997 (Street et al., 1998), the $d f w^{2 J}$ locus was transferred via serial backcrosses to $\mathrm{CBA} / \mathrm{CaJ}$ mice acquired directly from The Jackson Laboratory to maintain isogeneity with the commercially available inbred stock. The congenic animals used in this study were from backcross generations N6 (the 18-month-old animals) and N8 (the younger animals). Agematched littermate controls were used throughout. The L7-green fluorescent protein (GFP)-expressing mice were a gift from Dr. Michisuke Yuzaki (St. Jude Children's Research Hospital, Memphis, TN). All experimental animals used in this study were raised in a $12 \mathrm{~h}$ light/dark cycle in the University of Washington animal facility. Mice used for electroretinogram (ERG) recordings were maintained in a $12 \mathrm{~h}$ light/dark cycle. Genotyping was performed using allele-specific PCR primers (for details, see http://depts.washington.edu/tempelab/Protocols).

\section{Histological analysis}

For histological analysis, mice were killed with carbon dioxide inhalation and immediately perfused intracardially with a mixture of aldehydes $(2 \%$ paraformaldehyde and 2.5\% glutaraldehyde). Eyes were removed, bisected along the vertical meridian, postfixed in osmium tetroxide, and embedded in an Epon-Araldite mixture. Sections of the entire retina were cut at $1 \mu \mathrm{m}$ thickness and stained with toluidine blue as described previously (LaVail and Battelle, 1975). Tissue sections were chosen in which the rod outer segment (OS) and Müller cell processes crossing the inner plexiform layer (IPL) were continuous in the plane of section, or nearly so, to ensure that the sections were not oblique (Duncan et al., 2003).

\section{Immunocytochemistry}

The eyes were enucleated, corneas were cut with a razor blade, and the eyecups with the retinas were immersion fixed at room temperature for $0.5 \mathrm{~h}$ in $4 \%(\mathrm{w} / \mathrm{v})$ paraformaldehyde in $0.1 \mathrm{~m}$ phosphate buffer, $\mathrm{pH}$ 7.4. The retinas were rinsed two times in phosphate buffer and cryoprotected in $30 \%$ sucrose overnight at $4^{\circ} \mathrm{C}$. Pieces of retinas were mounted in OCT, sectioned vertically at $14 \mu \mathrm{m}$ thickness on a cryostat, collected on SuperFrost Plus slides (Fisher, Pittsburgh, PA), and stored at $-20^{\circ} \mathrm{C}$ until use. Rabbit polyclonal antibodies NR1, NR2, and NR3 against PMCA1, PMCA2, and PMCA3, respectively, were generated against $13-18$ residue peptide sequences at the $\mathrm{N}$ terminus of the corresponding rat PMCA (Filoteo et al., 1997) or against an N-terminal sequence of the human
PMCA1-PMCA4 (Stauffer et al., 1995). The NR1-NR3 antibodies were a kind gift from Drs. Strehler and Penniston (Mayo Clinic, Rochester, $\mathrm{MN}$ ) or were purchased from Affinity BioReagents (Golden, CO) and Swiss Antibodies (Swant, Bellinzona, Switzerland) and used at 1:200-1: 300. The RIBEYE antibody was a gift from Dr. Thomas Südhof (Texas Southwestern Medical Center, Dallas, TX). Postsynaptic density-95 (PSD-95) and sarco(endo)plasmic reticulum $\mathrm{Ca}^{2+}$ ATPase antibodies were obtained from Chemicon (Temecula, CA), glutamine synthetase antibodies were from BD Biosciences (San Jose, CA), and the protein kinase $C$ antibody was from Santa Cruz Biotechnology (Santa Cruz, CA). Synaptic vesicle protein 2 (SV2) antibody was developed by Kathleen Buckley (Harvard Medical School, Cambridge, MA) and obtained from the Developmental Studies Hybridoma Bank (Iowa City, IA). Fluorescein-conjugated peanut agglutinin (PNA) (Invitrogen, Carlsbad, CA) was used at 1:25.

\section{Western blot}

Cytoplasmic and nuclear proteins were prepared using the NE-PER extraction reagents (Pierce, Rockford, IL). The protein concentrations were determined by BCA protein assay kit (Pierce). Fifteen to $20 \mu \mathrm{g}$ of extract were resolved on NOVEX-NuPAGE 4-12\% BT gels (Invitrogen) and transferred to polyvinylidene difluoride membranes (Invitrogen). After 15-30 min incubation with StartingBlock blocking buffer (Pierce), the membranes were incubated in primary antibody at $4^{\circ} \mathrm{C}$ overnight. After washing, the blots were then incubated with appropriate antiperoxidase-conjugated secondary antibodies (1:4000; Amersham Biosciences, Arlington Heights, IL) at room temperature for 2-3 h. Finally, the proteins on the membranes were detected using the ECL Plus chemiluminescence system (Amersham Biosciences). The blots were stripped with Restore Western blot stripping buffer (Pierce) at room temperature for $60 \mathrm{~min}$ and then reprobed with different antibodies. Finally, the blots were probed with glyceraldehyde-3-phosphate dehydrogenase (GAPDH) as an internal loading control. Each experiment was repeated two to three times with independent samples from different animals.

\section{Quantitative PCR methods}

Six-week-old $d f w^{2 J}$ and control littermates were dark adapted for at least $30 \mathrm{~min}$ before the animals were killed by cervical dislocation. The retinas were dissected from the eyes in RNase free PBS and transferred immediately to RNAlater (Qiagen, Valencia, CA) for at least $30 \mathrm{~min}$ on ice. Liquid was removed and retinas were stored at $-80^{\circ} \mathrm{C}$ until additional processing. RNA was isolated using the RNeasy Micro kit (Qiagen) per the instructions of the manufacturer, with a single retina constituting a single sample. Carrier tRNA was not added. There was no significant difference between the yield of normal and mutant retinas (control littermates, $\left.1.99 \pm 0.73 \mu \mathrm{g} ; d f w^{2 J}, 1.81 \pm 0.75 \mu \mathrm{g} ; p=0.68\right)$.

$c D N A$ synthesis. One microgram of total RNA was incubated with $1 \mu \mathrm{l}$ (50 pM) of Random Hexamers (Applied Biosystems, Foster City, CA) in $9.5 \mu \mathrm{l}$ of reaction for $10 \mathrm{~min}$ at $70^{\circ} \mathrm{C}$, followed by immediate transfer to ice. To each reaction was added $4 \mu \mathrm{l}$ of $5 \times$ first-strand buffer (Clontech, Mountain View, CA), $2 \mu$ l of DTT (20 mM), $2 \mu$ l of dNTP (10 mм each), $0.5 \mu \mathrm{l}$ of Rnasin (Promega, Madison, WI), and $1 \mu \mathrm{l}$ of Powerscript Reverse Transcriptase (Clontech). The reaction $(20 \mu \mathrm{l})$ was incubated for $90 \mathrm{~min}$ at $42^{\circ} \mathrm{C}$, followed by $10 \mathrm{~min}$ at $72^{\circ} \mathrm{C}$. cDNAs were then diluted to $200 \mu \mathrm{l}$ final volume in $10 \mathrm{~mm}$ Tris and $0.1 \mathrm{~mm}$ EDTA, $\mathrm{pH} 8$.

Quantitative PCR primer design and validation. For each transcript of interest, quantitative PCR (qPCR) primers were designed using Primer3 software (Rozen and Skaletsky, 2000). Design criteria included the following: amplicons were chosen to be $50-150 \mathrm{bp}$ in length, primers were designed with melting temperature between 60 and $64^{\circ} \mathrm{C}$, guanine-cytosine base content was between 35 and $65 \%$, and the complementarity between and within primers was stringently minimized (Table 1). To verify that each primer set produced a single product of the correct size, a pilot $\mathrm{qPCR}$ experiment was run, using the same conditions as were used in all subsequent experiments. This consisted of a $25 \mu \mathrm{l}$ reaction, containing $12.5 \mu \mathrm{l}$ of $2 \times$ iQ SybR Green Supermix (Bio-Rad, Hercules, CA), $300 \mathrm{~nm}$ each primer (final concentration), and cDNA template (from adult mouse brain, from equivalent of $5 \mathrm{ng}$ starting total RNA). The cycling parameters (for amplification plus melting curve) were as fol- 
Table 1. Series of candidate reference genes quantified via qPCR

\begin{tabular}{|c|c|c|c|c|}
\hline Gene ID & Gene name & $5^{\prime}$ primer & $3^{\prime}$ primer & $\begin{array}{l}\text { Product } \\
\text { size }\end{array}$ \\
\hline Actg & $\begin{array}{l}\text { Actin } \\
\text { Tyrosine 3-monooxygenase/tryptophan 5-mono- }\end{array}$ & GAAGGAGATCACAGCCCTAGCA & GACAGTGAGGCCAGAATGGAG & 108 \\
\hline Ywhaz & oxygenase activation protein, $\zeta$ polypeptide & AGTCGTACAAAGACAGCACGCTAA & AGGCAGACAAAGGTTGGAAGG & 138 \\
\hline Pmca1 & Plasma membrane calcium ATPase isoform 1 & GCCATAGTATCATTGGGCCTTTC & ATCGCAGCTCCTTCAATCCA & 125 \\
\hline Pmca2 & Plasma membrane calcium ATPase isoform 2 & ACTCCTGGGTCAGCATTCC & TAGTAGCACGAGGCGGTCA & 148 \\
\hline Pmca3 & Plasma membrane calcium ATPase isoform 3 & GGCCTCTCCTTCTATGCACCTC & CTGCCCCACCAGACACATTC & 67 \\
\hline Pmca4 & Plasma membrane calcium ATPase isoform 4 & TCCCAGTGGCTGAGATTGTG & TCTTCAGATCATTTCCCTGGATTAG & 99 \\
\hline
\end{tabular}

lows: $95^{\circ} \mathrm{C}$ for $3 \mathrm{~min}$ (activate enzyme), 40 repeats of $95^{\circ} \mathrm{C}$ at $30 \mathrm{~s}, 60^{\circ} \mathrm{C}$ at $30 \mathrm{~s}$ (amplification), $95^{\circ} \mathrm{C}$ at $1 \mathrm{~min}, 55^{\circ} \mathrm{C} \times 1 \mathrm{~min}$ (premelt curve), and 90 repeats of $10 \mathrm{~s}$ each starting at $55^{\circ} \mathrm{C}$ and incrementing $0.5^{\circ} \mathrm{C}$ per step (melt curve). The melt curves for each primer set were inspected to ensure that only a single peak was present. A small amount of the product was also run on a $2.5 \%$ agarose gel to verify product size. All primer efficiencies were verified to be $100 \pm 5 \%$ via standard curve.

Reference gene selection. To compare expression levels between samples, we normalized gene-of-interest expression levels to the geometric mean of multiple control genes, offering a far more robust normalization than can be achieved using a single reference gene such as $\alpha$-actin or GAPDH (Vandesompele et al., 2002). Briefly, reference gene selection is performed as follows. For all of the samples to be assayed in a given study, the expression of a series of candidate reference genes (Table 1) is quantified via qPCR. These expression data are entered into the geNORM software (http://medgen.ugent.be/ jvdesomp/genorm/). This Microsoft (Seattle, WA) Excel-based algorithm evaluates all of the candidate genes and ranks them in order of stability across the sample set. Use of the two most stable reference genes was sufficient (using additional genes added little to the overall stability of the normalization scheme).

qPCR quantification and normalization. qPCR was performed using the reaction conditions described in the validation section above, for both the genes of interest and reference genes. Within a single qPCR experiment, each data point consisted of the average threshold cycle number from two experimental replicates (same biological sample, same reaction mixture). For each data point, normalized $P M C A$ gene expression was calculated by the formula: pmca $_{\mathrm{i}} / r=2^{n p i} /\left(2^{n r 1} \times 2^{n r 2}\right)^{1 / 2}$, where $\mathrm{pmca}_{\mathrm{i}}$ is the target gene copy number (for PMCA1, PMCA2, PMCA3, or PMCA4), $r$ is the geometric mean of the two reference gene copy numbers, $n p_{i}$ is the threshold cycle number for $\mathrm{PMCA}_{\mathrm{i}}$, and $n r_{\mathrm{i}}$ is the threshold cycle number for reference gene $r_{i}$. Final reported values were based on three independent qPCR runs from three animals of each genotype (for details, see Results).

\section{Electroretinographic analysis}

Full-field ERGs were recorded from $d f w^{2 J}$ and control littermates as described previously (Bok et al., 2002). Briefly, mice were dark adapted overnight and anesthetized with ketamine $(87 \mathrm{mg} / \mathrm{kg})$ plus xylazine (13 $\mathrm{mg} / \mathrm{kg}$ ), pupils were dilated with $2.5 \%$ phenylephrine and $1 \%$ atropine in dim red light, and mice were kept on a warming blanket. Contact lens electrodes for mice (Bayer et al., 1999) were placed on the corneal surfaces bilaterally with $1 \%$ methylcellulose, and silver wire reference and ground electrodes were placed subcutaneously in the nose and tail, respectively. Using a UTAS-E 3000 Visual Diagnostic System (LKC Technologies, Gaithersburg, MD) and beginning below ERG threshold, stimuli were presented in order of increasing luminance from -4.6 to +0.4

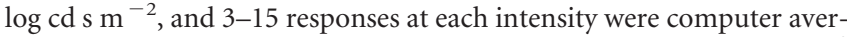
aged. If we assume that a Ganzfeld stimulus of 1 scotopic ( $\operatorname{scot}) \mathrm{cd} \mathrm{s} \mathrm{m}^{-2}$ produces 500 photoisomerizations per mouse rod $\left(\mathrm{Rh}^{*}\right)$, between estimates in the literature of 100 (Hetling and Pepperberg, 1999) and 1500 (Pennesi et al., 1998), these stimulus intensities ranged from 0.012 to $5 \times$ $10^{6} \mathrm{Rh}^{*}$; thus, $100 \mathrm{Rh}^{\star}$ was produced by approximately $-0.5 \log \operatorname{scot} \mathrm{cd}$ $\mathrm{s} \mathrm{m}^{-2}$. Interstimulus intervals ranged from $5 \mathrm{~s}$ at the lowest intensities to $120 \mathrm{~s}$ at the highest intensities. The amplitude and time-to-peak of the aand b-waves were measured. Below a-wave threshold, b-wave amplitudes were measured from baseline to peak; at intensities in which measurable a-waves were present, b-wave amplitudes were measured from the a-wave trough to the b-wave peak.

A subset of $d f w^{2 J}$ and control mice were prepared for ERG analysis using infrared goggles in the absence of any dim red light to record the scotopic threshold response (STR) after overnight adaptation and exposed to stimuli presented in order of increasing luminance from -6.6 $\log \mathrm{cd} \mathrm{s} \mathrm{m}{ }^{-2}$. In addition, responses to a single flash of $+2.4 \log \mathrm{cd} \mathrm{s} \mathrm{m}{ }^{-2}$ were recorded from a subset of $d f w^{2 J}$ and control mice. Mice were exposed to a background light of $30 \mathrm{~cd} \mathrm{~s} \mathrm{~m}^{-2}$ for $10 \mathrm{~min}$ before recording photopic responses to stimuli presented at a rate of $2 \mathrm{~Hz}$ at $0.4 \log \mathrm{cd} \mathrm{s}$ $\mathrm{m}^{-2}$. Because photopic a-waves are negligible in mice (Peachey et al., 1993), the amplitude and time-to-peak of the photopic b-waves were measured.

\section{Suction recordings}

Outer segment currents from single rod photoreceptors were recorded using suction electrodes (Baylor et al., 1979; Field and Rieke, 2002). Mice were dark adapted for $12-15 \mathrm{~h}$, and the retinas were isolated under infrared illumination $(>950 \mathrm{~nm})$. Brief flashes were delivered from a lightemitting diode with peak output at $470 \mathrm{~nm}$. Calibrated flash strengths were converted to photoisomerizations $\left(\mathrm{Rh}^{*}\right)$ assuming a collecting area of $0.5 \mu \mathrm{m}^{2}$. Cells were continuously superfused with bicarbonatebuffered Ames' solution (Sigma, St. Louis, MO) warmed to $36-37^{\circ} \mathrm{C}$.

\section{Retinal slice preparation and whole-cell recording}

Current responses of rod bipolar cells were recorded using whole-cell, voltage-clamp recordings in retinal slices prepared as described previously (Armstrong-Gold and Rieke, 2003). The internal solution contained the following (in $\mathrm{mm}$ ): $125 \mathrm{~K}$-aspartate, $10 \mathrm{KCl}, 10$ HEPES, 5 NMG-HEDTA, 0.5 $\mathrm{CaCl}_{2}$, 1 ATP-Mg, and 0.2 GTP-Mg, pH 7.2 (osmolarity was $275-285 \mathrm{mOsm}$ ). Slices were continuously superfused with Ames' solution warmed to $36-37^{\circ} \mathrm{C}$. Light delivery and calibration were similar to that for the rod recordings. Rod bipolar cells were identified based on a soma location in the outermost part of the inner nuclear layer (INL) and characteristic light responses.

\section{Statistical analysis}

Most ERG responses from $d f w^{2 J}$ and control mice were compared using a Student's $t$ test. Values are presented as mean \pm SEM unless otherwise noted. $p$ values $<0.05$ were considered significant.

\section{Results}

To test for a role of PMCA2 in retinal development or in the transmission of rod- and cone-mediated signals across the retina, we measured the expression pattern of PMCA2 and compared the histology and light responses of retinas lacking PMCA2 with normal retinas. As described below, absence of PMCA2 did not produce clear histological changes but did alter the transmission of rod-mediated signals.

\section{PMCA2 is abundant in the retina but is not required for normal development}

Levels of PMCA2 expression in control and $\mathrm{dfw}^{2 \mathrm{~J}}$ retinas

The retinal homogenates from homozygous $\mathrm{dfw}^{2 J}$ mice and control mice were analyzed by Western blotting with a polyclonal 


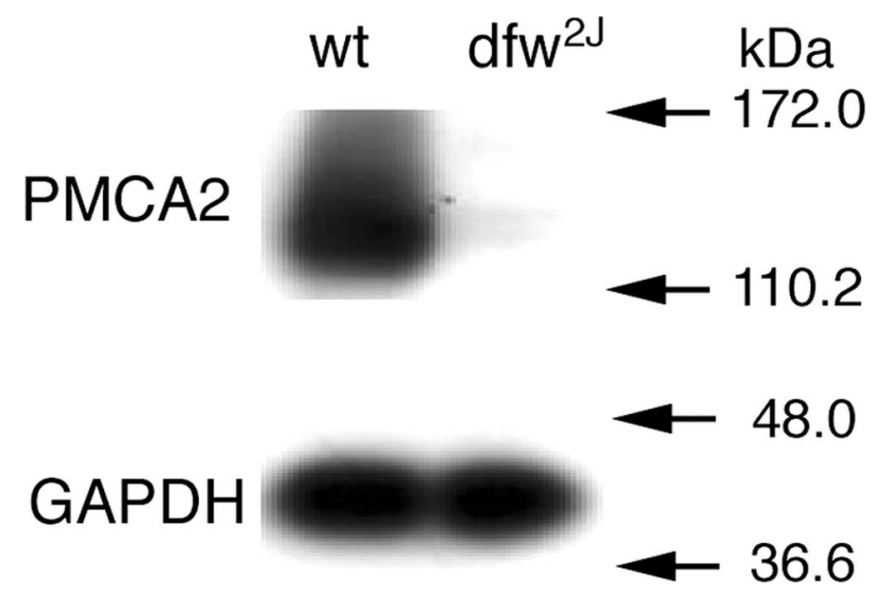

Figure 1. PMCA2 is not expressed in the $d f w^{2 J}$ mouse retina. Representative Western blots of PMCA2 from control and $d f w^{2 J}$ retinas. Total protein lysates (15-25 $\mu \mathrm{g}$ of protein per lane) were processed for Western blotting by using specific antibodies. Molecular weight standards are indicated in kilodaltons on the side and are marked by arrows. WT, Wild type.

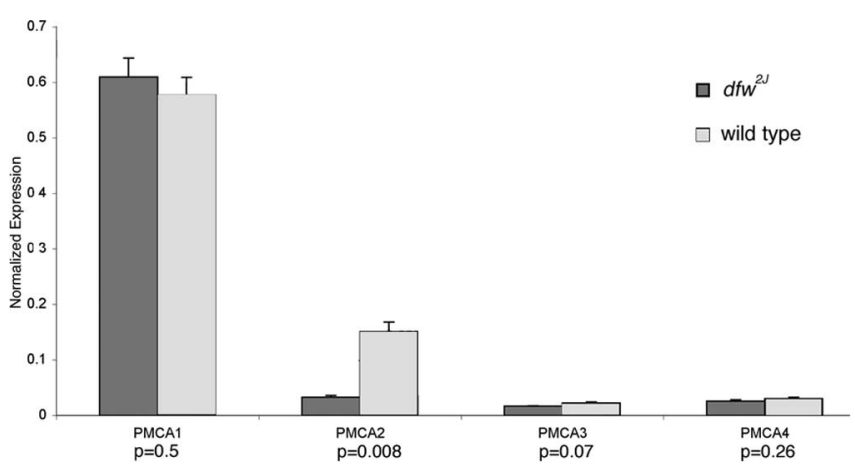

Figure 2. PMCA mRNA expression control and $d f w^{2 J}$ mouse retina. $q P C R$ analysis of transcript level of PMCA1, PMCA2, PMCA3, and PMCA4 demonstrates that there is no significant compensatory changes in expression of any of the PMCA isoforms in the $\mathrm{dfw}^{2 J}$ mouse. Data shown are obtained from six retinas that were individually analyzed from three animals of each genotype. Each bar in the figure represents the average across the six samples of three independently run experimental replicates. Error bars denote SEM.

PMCA2-specific antibody and by reverse transcription (RT)PCR. In the control, the antibody recognized a single band of $\sim 140 \mathrm{kDa}$ (Strehler and Zacharias, 2001; Križaj et al., 2002) (Fig. 1). The $d f w^{2 J}$ mice are functionally null because of a frame shift in the coding sequence (Street et al., 1998; McCullough and Tempel, 2004). Accordingly, little or no PMCA2 protein was detected in the retinal homogenate derived from the $d f w^{2 J}$ homozygotes (Fig. 1).

Previous studies suggested that all four PMCA isoforms are expressed in the vertebrate retina (Križaj et al., 2002, 2004; Rentería et al., 2005). Quantitative real-time RT-PCR was performed to assess the abundance of PMCA transcripts in the mouse retina. The cDNA values for all transcripts were normalized to the geometric mean of the expression levels of two reference genes: ACTG (actin) and YWHAZ (tyrosine 3-monooxygenase/tryptophan 5-monooxygenase activation protein, $\zeta$ polypeptide). As shown in Figure 2, PMCA1 accounted for $\sim 80 \%$ of the PMCA transcript in the mouse retina and PMCA2 for 20\%; PMCA3 and PMCA4 were expressed at much lower levels.

Loss of PMCA2 could trigger compensatory upregulation of other PMCA isoforms (Guerini et al., 1999; Brini et al., 2003; Wood et al., 2004). To determine whether transcripts encoding PMCA 1, PMCA3, and/or PMCA4 are upregulated in $d f w^{2 J}$ reti- nas, qPCR was performed in parallel on $d f w^{2 J}$ retinas. Small, statistically insignificant changes in PMCA1, PMCA3, and PMCA4 expression were observed in $d f w^{2 J}$ retinas (Fig. 2). The PMCA2 transcript detected in $d f w^{2 J}$ retinas is attributable to incomplete degradation (McCullough and Tempel, 2004).

These results show that PMCA2 is the second most abundant PMCA2 isoform in the mouse retina. The absence of compensatory upregulation of PMCA1, PMCA3, and PMCA4 isoforms suggests that a $d f w^{2 J}$ phenotype is likely associated with the loss of PMCA2.

\section{PMCA2 is expressed in inner and outer retina}

PMCA2 immunolocalization in control (littermate) mice revealed that PMCA2 is found in both inner and outer retina as well as in the retinal pigment epithelium (Fig. 3). No PMCA2 signal was detected in $d f w^{2 J}$ retinas immunostained with PMCA2 antibodies (Fig. 3D). As shown previously (Križaj et al., 2002), PMCA2 was strongly expressed in the inner retina of the mouse. PMCA2 immunoreactivity was detected in the majority of amacrine perikarya in the adult mouse. The immunoreactivity observed in two brightly stained bands corresponds to cell processes of cholinergic amacrine cells (Rentería et al., 2005). At higher confocal gain, PMCA2 immunoreactivity was detected in rod inner segments (ISs) (Fig. 3B, arrowheads), in the outer plexiform layer (OPL) (Fig. $3 C$, arrows), in the inner nuclear layer, and in the retinal pigment epithelium (Fig. $3 A$ ); PMCA2 signal was absent from rod OSs (Fig. $3 B, C$ ). The IS labeling was observed with two different anti-PMCA2 antibodies, raised against rat and human epitopes. PMCA2 localization to ISs was not described in our previous report (Križaj et al., 2002) probably because the PMCA2 signal in the IS is much weaker than that in the inner retina and the signal is better seen in retinas fixed for shorter time periods (Rentería et al., 2005).

To determine whether PMCA2 is expressed early in development of the mouse retina, we examined retinal sections from postnatal day 1 (P1) to $\mathrm{P} 35$ mice. At P1, PMCA2 was found in the IPL with a moderate expression in the neuroblast layer (NBL) (Fig. 3). No signal was observed in the absence of the primary antibody (Fig. 3A). The IPL signal remained prominent throughout development. At P5, PMCA2 immunoreactivity was detected in the developing OPL in addition to the ganglion cell layer and the NBL. From P7 up to adult, there was a gradual retraction in PMCA2 immunoreactivity from the outer nuclear layer (ONL) and INL into both plexiform layers (Fig. $3 A$ ), with a moderate PMCA2 signal visible at higher confocal gains throughout the INL. These results indicate that, in the mouse retina, PMCA2 is already widely expressed at birth in both cell bodies and cell processes; during maturation, PMCA2 expression becomes mainly confined to both synaptic layers.

The presynaptic and postsynaptic localization in the OPL was studied in colocalization experiments. The PDZ (postsynaptic density-95/Discs large/zona occludens-1) domain-containing protein PSD-95 is a marker for photoreceptor terminals in the mouse retina. As illustrated in Figure 4B, PMCA2 overlapped with PSD-95-immunoreactive structures in the OPL, suggesting that it is expressed in synaptic terminals of rods. To determine whether PMCA2 is also localized to cone synapses, retinas were double immunostained with the FITC-conjugated cone marker PNA. PNA labeled cone outer segments as well as a row of OPL puncta corresponding to cone pedicles (Fig. 4A). PMCA2 staining was specifically excluded from PNA-positive structures (Fig. $1 A$, Aii). The localization of PMCA2 to rod spherules and its 

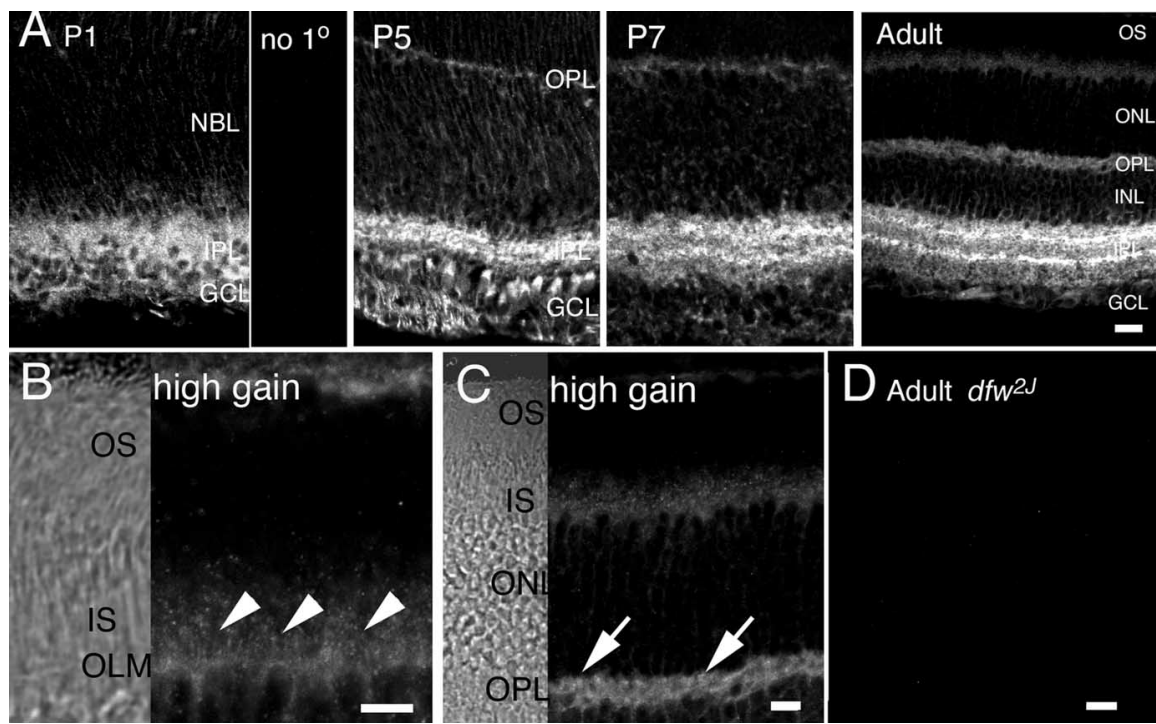

Figure 3. PMCA2 expression and localization in the control and $d f w^{2 J}$ mouse retina. $A$, Control mouse retinal sections labeled with polyclonal antibodies raised against PMCA2. PMCA2 is expressed throughout the postnatal development. At P1, the PMCA2 antibody labels both inner retina and the neuroblast layer. No PMCA2 signal is seen in the absence of the primary antibody. During maturation, the PMCA2 signal gradually retracts from the developing ONL and INL; in the adult, PMCA2 is predominantly expressed in the inner retina, with moderate expression in ganglion cells and photoreceptors. Two brightly stained PMCA2immunopositive bands are seen in sublaminae $a$ and b, respectively. Scale bar, $20 \mu \mathrm{m}$. $\boldsymbol{B}, \boldsymbol{C}$, Magnified view of the outer retina obtained at higher confocal gain. PMCA2 is expressed in inner segments of rod photoreceptors (arrowheads in $\boldsymbol{B} ;$ scale bar, $5 \mu \mathrm{m}$ ) and photoreceptor terminals (arrows in $\boldsymbol{C}$; scale bar, $10 \mu \mathrm{m}$ ). $\boldsymbol{D}$, Little PMCA2 immunoreactivity is observed in the $d f w^{2 J}$ mouse retina. Scale bar, $20 \mu \mathrm{m}$. OLM, Outer limiting membrane; $\mathrm{GCL}$ ganglion cell layer.

absence from pedicles is consistent with a presynaptic role for PMCA2 at rod, but not cone, synapses.

Double staining with the rod bipolar cell marker protein kinase $\mathrm{C}$ suggested that PMCA2 is expressed in cell bodies and dendrites of rod bipolar cells (Fig. 4D, arrows). PMCA2 immunoreactivity was localized to the dendritic region of rod bipolar cells and in bipolar perikarya (Fig. 4C,D). Immunostaining of retinas from transgenic mice that express high levels of GFP in rod bipolar cells (Tomomura et al., 2001) additionally suggested postsynaptic localization of PMCA2 to rod bipolar cells (Fig. 4C, arrowheads). A subset of INL neurons that did not express GFP was PMCA2 immunoreactive (Fig. 4C, right panel, arrow), suggesting possible localization to cone bipolar neurons. Finally, PMCA2 antibodies labeled the majority of neurons at the proximal edge of the INL, corresponding to amacrine cells (Fig. 3).

To determine PMCA2 expression in radial glia that envelop the synaptic terminals of rods and cones (Sarantis and Mobbs, 1992) and regulate development (Rich et al., 1995) and visual responses of retinal neurons (Newman, 2004), retinas were immunostained with the Müller cell marker glutamine synthetase. PMCA2 partially colocalized with glutamine synthetase at the level of the outer limiting membrane (Fig. $4 E$ ), in the OPL and INL (Figs. $4 E, F$ ), suggesting that PMCA-mediated $\mathrm{Ca}^{2+}$ extrusion regulates Müller cell $\mathrm{Ca}^{2+}$ homeostasis. Together, these data suggest that PMCA2 is expressed in the OPL at presynaptic and postsynaptic locations comprising the rod pathway and glial processes but is excluded from cones.

To determine whether the changes in kinetics of visual transmission in $d f w^{2 J}$ mice (see below) were associated with altered expression of synaptic markers, we examined the expression of the several presynaptic proteins in $d f w^{2 J}$ mice as well as that of PMCA1, the major PMCA isoform expressed in rod and cone terminals (Križaj et al., 2002; Rentería et al., 2005). Confocal analysis of PMCA1, the synaptic ribbon protein RIBEYE, and the synaptic marker SV2 expression found no major differences in the pattern of immunostaining for these proteins (data not shown). Furthermore, the expression of rod bipolar cell marker protein kinase $\mathrm{C}$, horizontal cell marker calbindin, GABAergic amacrine cell marker GAD-65, and the Müller cell marker glutamine synthetase was not qualitatively different from controls (data not shown).

Retinas from $\mathrm{dfw}^{2 \mathrm{~J}}$ mice are anatomically normal

Given the prominent PMCA2 expression in the retina (Figs. 1-4) and massive degeneration of cochlear and vestibular structures in PMCA2-deficient mice (Street et al., 1998; Dodson and Charabalapoulou, 2001), it was of interest to determine whether retinal anatomy was compromised in $\mathrm{dfw}^{2 J}$ mice. No differences were apparent in length or density of rod OS, ONL thickness, ONL cell count, or the combined thickness of the OS and IS layers in retinal sections from $\mathrm{P} 65 d f w^{2 J}$ mice and their littermate controls. No degradation in the inner retina was apparent at the light microscopic level ( $n=5$ ) (Fig. 5). No evidence of cellular degeneration was found in any $d f w^{2 J}$ mice compared with littermate controls examined at up to 18 months of age (data not shown).

The results summarized in Figures $1-5$ indicate that PMCA2 is expressed in several locations in the retina but is not required for normal development and maintenance of retinal layers. We next tested for a role of PMCA2 in the generation and transmission of light responses in the retina.

\section{Loss of PMCA2 alters transmission of rod-mediated signals} We used ERGs and single-cell recordings to evaluate the importance of PMCA2 for the transmission of rod-mediated signals through the retina. As described below, the kinetics and sensitivity of scotopic (i.e., rod-mediated) ERGs were altered in mice lacking PMCA2. Responses of single rod outer segments were not significantly altered, whereas those of rod bipolar cells were. Together, these results indicate a role of PMCA2 in the normal transmission of signals from rod outer segments to rod bipolar cells.

Scotopic ERG responses in $\mathrm{dfw}^{2 \mathrm{~J}}$ mice are reduced and delayed ERGs represent the summed activity of rods and downstream retinal cells and thus provide an effective means to identify deficits in signaling. Figure 6 shows representative scotopic ERG recordings for control and $\mathrm{dfw}^{2 J}$ mice. The STR is a cornea-negative waveform that originates in the inner retina (Sieving and Nino, 1988; Robson and Frishman, 1995; Saszik et al., 2002) and is the highest sensitivity component of the ERG. Compared with control $\left(-5.1 \pm 0.2 \log \mathrm{cd} / \mathrm{s} / \mathrm{m}^{-2}(n=12\right.$ eyes, 6 mice $)$, the $d f w^{2 J}-/-$ STR threshold was elevated $\left(-4.4 \pm 0.04 \log \mathrm{cd} \mathrm{s} \mathrm{m}^{-2}\right.$ (Fig. 6 , arrows) $(n=8$ eyes, 4 mice; $p=0.001)$. Thus, loss of PMCA2 reduced inner retinal sensitivity at rod threshold intensities.

Signaling in the outer retina was assayed from the a-wave, which reflects primarily signals in rod photoreceptors (Granit, 
1947; Penn and Hagins, 1969; Lyubarsky and Pugh, 1996), and the b-wave, which at low light levels primarily reflects the integrated responses of rod bipolar cells (Masu et al., 1995; Robson and Frishman, 1995; Green and Kapousta-Bruneau, 1999).

The a-wave was reduced in amplitude and slowed slightly in the absence of PMCA2. In response to flashes producing $\sim 10^{5} \mathrm{Rh}^{\star} /$ rod, the a-wave in $d f w^{2 J}$ mice was $\sim 25 \%$ smaller than control (Fig. $7 A$ ) $(455 \pm 15 \mu \mathrm{V}$ for 22 control eyes vs $336 \pm$ $25 \mu \mathrm{V}$ for $24 d f w^{2 J}$ eyes; $\left.p<0.0001\right)$. These differences were first apparent for intensities producing $\sim 100 \mathrm{Rh}^{\star} / \mathrm{rod}$ (Fig. $7 C$ ). The time-to-peak for the maximum scotopic a-wave was slightly slowed (Fig. $7 B)(6.4 \pm 0.1 \mathrm{~ms}$ in control mice vs $6.8 \pm$ $0.08 \mathrm{~ms}$ in $d f w^{2 J}$ mice; $p=0.023$ ). Thus, flashes that saturated individual rods (see below) reduced the amplitude and slowed the kinetics of the summed rod response.

Loss of PMCA2 produced larger changes in the b-wave than a-wave. In response to flashes producing $\sim 10^{3} \mathrm{Rh}^{\star}$ I rod, b-waves from $d f w^{2 J}$ mice were reduced by $>45 \%$ compared with control (Fig. 7D) (818 $\pm 30 \mu \mathrm{V}$ in 26 control eyes, $445 \pm 32 \mu \mathrm{V}$ in $26 d f w^{2 J}$ eyes; $\left.p<0.0001\right)$. The reduction in b-wave amplitude was observed across a wide range of intensities (Fig. 7C), including intensities in which the rod a-wave responses were little affected. Thus, at $-4.6 \log \mathrm{cd} \mathrm{s} \mathrm{m}{ }^{-2}(\sim 0.01$ $\mathrm{Rh}^{*} /$ rod), the b-wave amplitude in control animals was $31 \pm 2 \mu \mathrm{V}$, whereas $d f w^{2 J}$ response was $17 \pm 2 \mu \mathrm{V}$, a $45 \%$ reduction (Fig. 7C). The time-to-peak of the maximum scotopic b-wave in $d f w^{2 J}$ mutants was also significantly delayed (Fig. 7E) (95 $\pm 2 \mathrm{~ms}$ in control vs $106 \pm 2 \mathrm{~ms}$ in $\left.d f w^{2 J} ; p<0.0001\right)$. The delay in the $d f w^{2 J}$ b-wave was still significant in responses matched for equal a-wave amplitudes (data not shown) and was apparent across a wide range of intensities (Fig. 7F).

At intermediate intensities, the reduction in b-wave amplitude and increased time-to-peak can likely be attributed to reduction in the summed rod bipolar responses, although, at low intensities, the b-wave is contaminated by the STR and, at high intensities, reflects activity of both rod and cone bipolar cells. The larger changes in amplitude and kinetics of the b-wave compared with the a-wave in $d f w^{2 J}$ mice suggest that PMCA2 plays a role in regulating the transmission of rod signals to rod bipolar cells. To test this suggestion directly, we recorded responses of individual rod outer segments and rod bipolar cells.
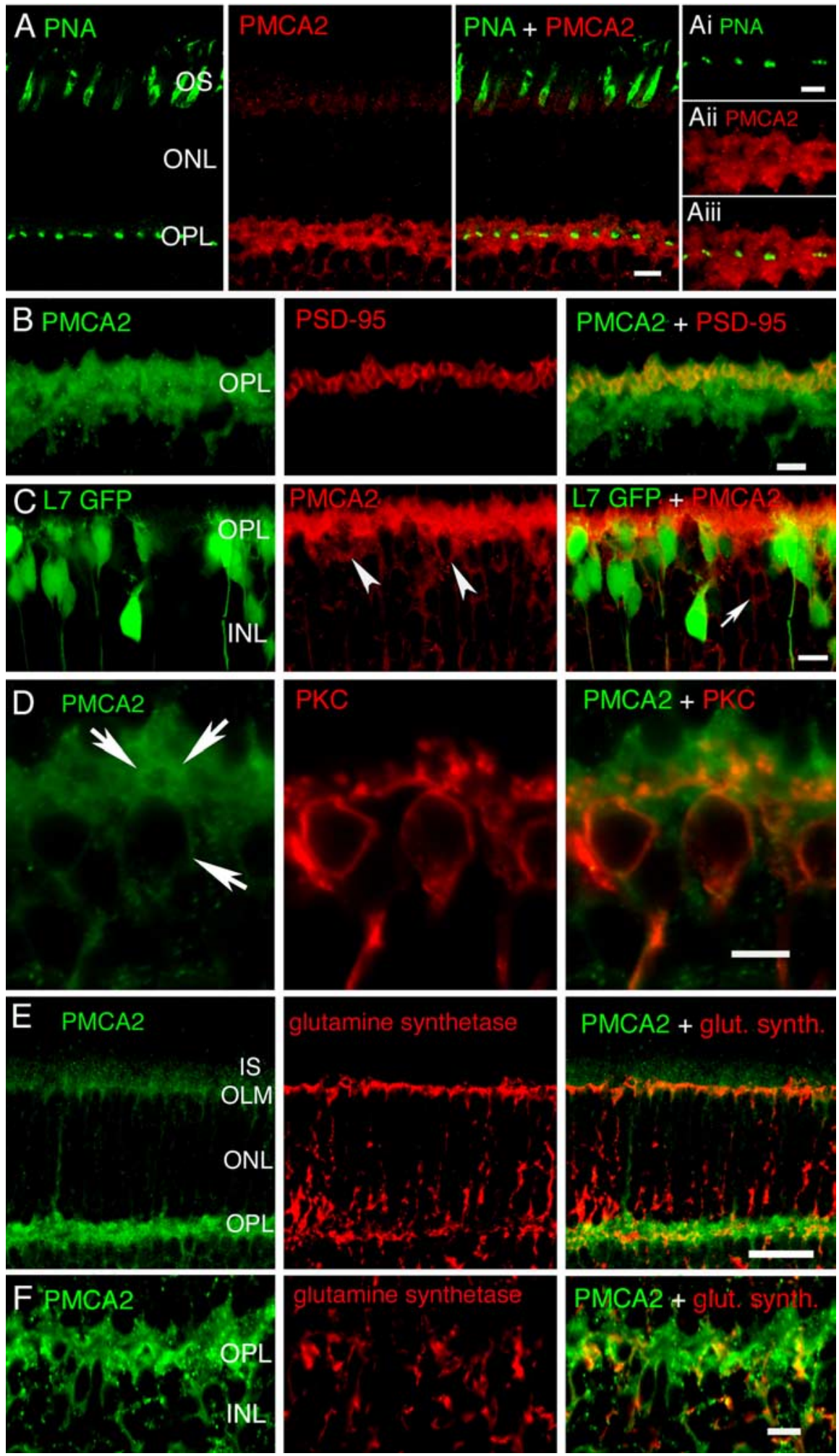

Figure 4. PMCA2 is expressed presynaptically and postsynaptically in the outer plexiform layer. $A, P M C A 2$ does not colocalize with the cone marker PNA. Scale bar, $10 \mu \mathrm{m}$. Ai-Aiii, High-resolution detail of the OPL. Scale bar, $5 \mu \mathrm{m}$. B, High-resolution image of the OPL double labeled with the photoreceptor terminal marker PSD-95 and PMCA2. Scale bar, $5 \mu \mathrm{m}$. C, Retinal section from L7 transgenic mice expressing GFP in rod bipolar cells. Cell bodies of rod bipolar cells express PMCA2 (middle, arrowheads). PMCA2 is also expressed in a subset of GFP-negative cells in the INL (right, arrow). Scale bar, $10 \mu \mathrm{m}$. D, High-resolution image of OPL double labeled with PMCA2 and the rod bipolar cell marker protein kinase C (PKC). Colocalization is observed in rod bipolar cell dendrites (arrows) and cell bodies. Scale bar, $5 \mu \mathrm{m} . \boldsymbol{E}, \boldsymbol{F}$, Double labeling for PMCA2 and the Müller cell marker glutamine synthetase. $\boldsymbol{E}$, Partial colocalization is observed in the outer limiting membrane (OLM) and OPL. Scale bar, $5 \mu \mathrm{m}$. $\boldsymbol{F}$, High-resolution image of the OPL labeled with PMCA2 and glutamine synthetase. Scale bar, $5 \mu \mathrm{m}$. 


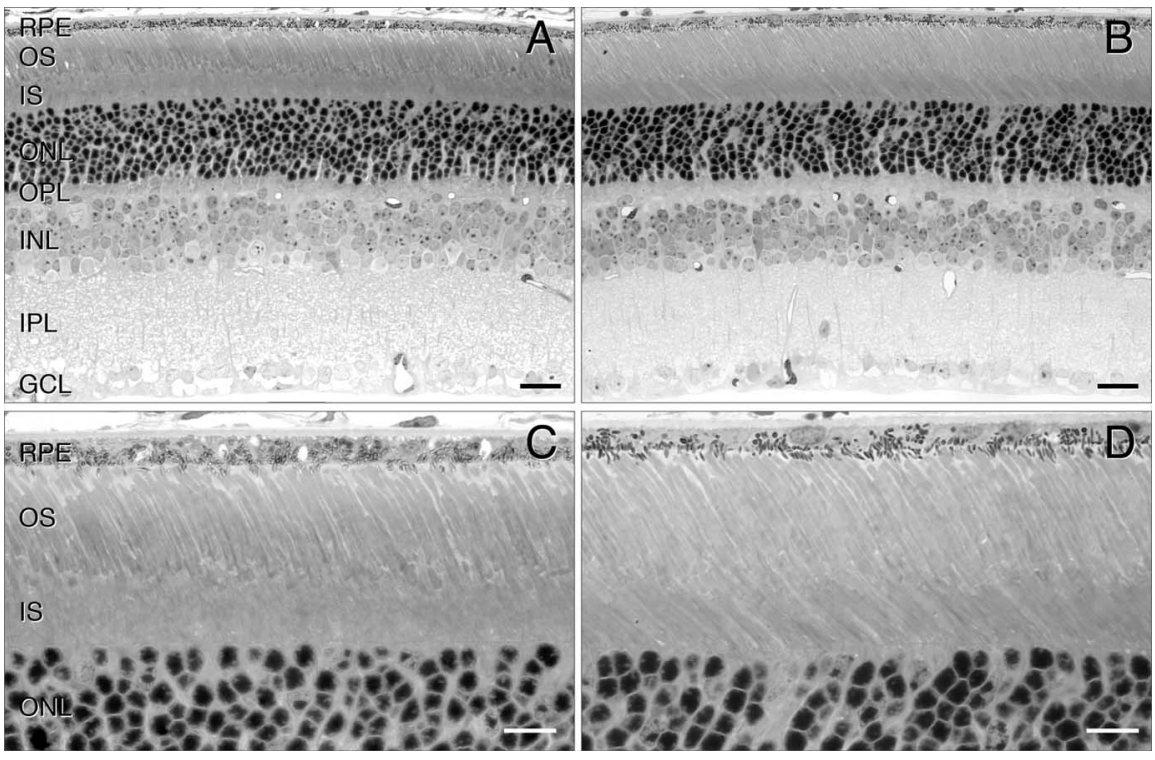

Figure 5. Retinal structures are normal in $d f w^{2 J}$ mice. Light micrographs of retinal sections from a control mouse $(\boldsymbol{A})$ and a $d f w^{2 J}$ littermate $(\boldsymbol{B})$ at P65. The $d f w^{2 J}$ retina has a normal appearance with no evidence of retinal degeneration. Scale bars, $20 \mu \mathrm{m}$. A higher-magnification view of slides $\boldsymbol{A}$ and $\boldsymbol{B}$ shows no abnormalities of the photoreceptor ONL, ISS, or OSs in control $(\boldsymbol{C})$ or $d f w^{2 J}(\boldsymbol{D})$ mice. Scale bars, $10 \mu \mathrm{m}$. RPE, Retinal pigment epithelium. and $d f w^{2 I}$ (Fig. $8 B$ ) rod. The qualitative features of the responses in the two types of rods were similar. Figure $8 C$ plots response amplitude against flash strength for 22 control and $25 d f w^{2 J}$ rods. The halfsaturating flash strength was $9.9 \pm 0.4 \mathrm{Rh}^{\star}$ for control rods and $10.5 \pm 0.4 \mathrm{Rh}^{*}$ for $d f w^{2 J}$ rods (mean \pm SEM). The kinetics of responses to flashes producing $1-5 \mathrm{Rh}^{*}$ were also similar (Fig. 8D). Responses to these flashes reached peak in $206 \pm 8 \mathrm{~ms}$ in control rods and $218 \pm 10 \mathrm{~ms}$ in $d f w^{2 J}$ rods. Finally, both types of rods had similar dark currents: $14.5 \pm 0.5 \mathrm{pA}$ in both control and $d f w^{2 J}$ rods. These results indicate that individual $d f w^{2 J}$ rod outer segments show normal or near-normal sensitivity to dim light and indicate that the phototransduction process in individual rods is not modulated by PMCA2. This differs from the conclusion reached from the ERGs, which indicated a reduction in the amplitude of the summed rod response; we return to this difference in Discussion.

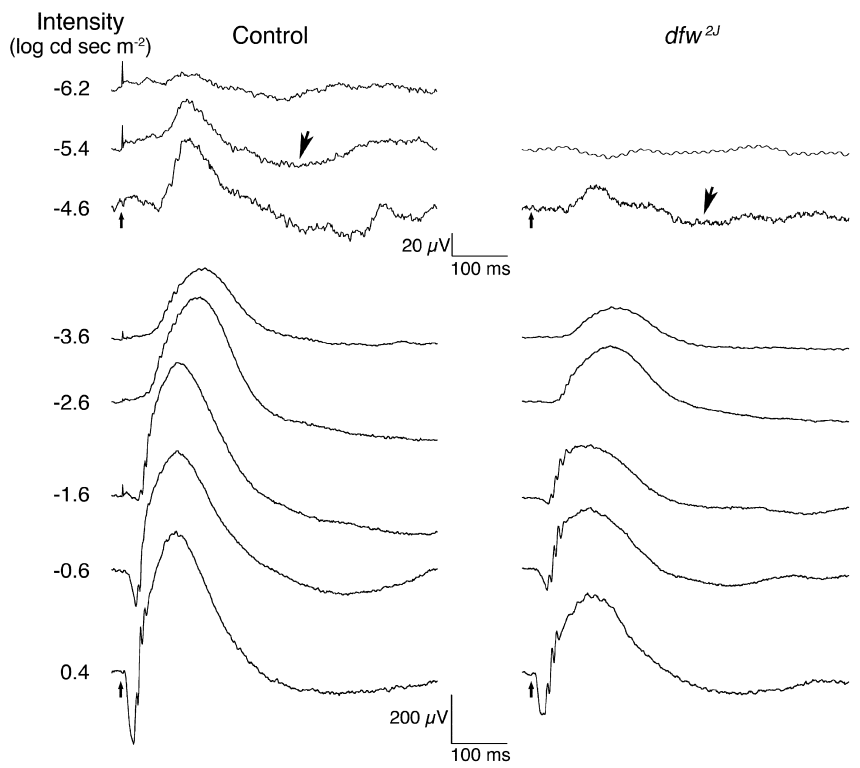

Figure 6. Mice homozygous for PMCA2 mutations have abnormal retinal function. Representative scotopic ERG waveforms from control (left) and $d \mathrm{fw}^{2 J}$ (right) mice in response to a series of white stimuli, beginning below the STR threshold and continuing to a bright $(0.4 \log \mathrm{cd}$ $\mathrm{sm}^{-2}$ ) flash. Small arrows indicate stimulus time, and small flash artifacts are present in some tracings. The STR thresholds (arrows) are elevated one-half log unit above control, and a- and b-wave amplitudes are lower in the $\mathrm{dfw}^{2 J}$ mouse.

\section{The photosensitivity of $\mathrm{dfw}^{2 \mathrm{~J}}$ rods is normal}

We used suction electrode recordings to determine whether the effect of PMCA2 on the summed rod responses indicated by the ERG measurements was indicative of the behavior of individual rod outer segments. As described below, these experiments indicated that rod outer segment light responses were near normal in the absence of PMCA2.

Figure $8, A$ and $B$, superimposes average responses to flashes producing between 2 and $200 \mathrm{Rh}^{\star}$ for a single control (Fig. $8 \mathrm{~A}$ )
Rod bipolar cell sensitivity in $\mathrm{dfw}^{2 \mathrm{I}}$ mice is reduced

To test for an effect of PMCA2 on signal transfer downstream from the rod outer segment, we recorded light responses of voltage-clamped rod bipolar cells in retinal slices. The sensitivity of the rod bipolar cells was reduced in $\mathrm{dfw}^{2 J}$ mice, indicating a role for PMCA2 in transmission of signals to the rod bipolar cell.

Light responses of rod bipolar cells from control and $d f w^{2 J}$ mice were qualitatively similar (Fig. 9A,B). Responses of $d f w^{2 J}$ rod bipolar cells, however, were $\sim 50 \%$ less sensitive than control rod bipolar cells (Fig. 9C); the half-saturating flash strength was $3.7 \pm 0.2 \mathrm{Rh}^{\star} / \mathrm{rod}$ for $d f w^{2 J}$ rod bipolars (mean $\pm \mathrm{SEM} ; n=11$ ) and $2.4 \pm 0.1 \mathrm{Rh}^{*} /$ rod for control rod bipolars $(n=61)$. Halfsaturating flash strengths for rod bipolar cells from littermate $d f w^{2 J}$ control mice $\left(2.6 \pm 0.1 \mathrm{Rh}^{\star} /\right.$ rod; $\left.n=18\right)$ and C57BL/6 mice $\left(2.4 \pm 0.1 \mathrm{Rh}^{*} /\right.$ rod; $\left.n=43\right)$ were similar; hence, responses from both genetic backgrounds were combined as controls. The kinetics of responses producing $<1 \mathrm{Rh}^{*} /$ rod were similar in control and $d f w^{2 J}$ rod bipolar cells (Fig. $9 D$ ); the time-to-peak was $157 \pm$ $5 \mathrm{~ms}$ in $d f w^{2 J}$ rod bipolar cells and $158 \pm 4 \mathrm{~ms}$ in controls. Saturating flashes in the rod bipolar (producing $\sim 20 \mathrm{Rh}^{\star} /$ rod) had a time-to-peak of $101 \pm 3 \mathrm{~ms}$ in control and $104 \pm 8 \mathrm{~ms}$ in mutants (mean $\pm \mathrm{SEM}$ ). The $\sim 5 \mathrm{~ms}$ difference in time-to-peak of the b-wave observed at comparable light levels would not be detected using this technique.

Both ERG and single-cell recordings indicate a greater disruption in signaling downstream of the rods than in the rods themselves. The single-cell recordings indicate that at least part of the differences observed in the ERGs can be attributed to a deficit in the transfer of signals from rod outer segments to rod bipolar cells in the absence of PMCA2.

\section{Loss of PMCA2 does not alter transmission of cone-mediated signals}

Results from experiments performed in scotopic conditions indicated that PMCA2 modulates signaling between rods and rod bipolar cells. As described below, loss of PMCA2 has little or no effect on cone-mediated ERGs. 
Photopic (cone-mediated) responses were recorded in response to single flashes after $30 \mathrm{~min}$ light adaptation at $30 \mathrm{~cd} \mathrm{~s}$ $\mathrm{m}^{-2}$. The photopic a-wave, caused by cone photoresponses, is very small in mice because of the small number of cones; thus, b-wave responses were measured at 2 $\mathrm{Hz}$ stimulation. Representative traces from control and $d f w^{2 J}$ mice are shown in Figure $10 \mathrm{~A}$. Figure $10 \mathrm{~B}$ shows that the amplitudes of photopic b-wave responses in $d f w^{2 J}$ mice were not significantly different from control littermates $(110.1 \pm 4.4 \mu \mathrm{V}$ in controls, $n=26$ eyes vs $102.1 \pm 5.5 \mu \mathrm{V}$ in $d f w^{2 J}$ mice, $\left.n=36 ; p=0.29\right)$. The b-wave time-to-peak was also similar in control and $d f w^{2 J}$ mice at $61.9 \pm 1 \mathrm{~ms}(n=$ 26 eyes) vs $63.9 \pm 1 \mathrm{~ms}$ in $d f w^{2 J}$ mice $(n=$ 36 eyes; $p=0.20$ ) (Fig. 10C). These results suggest that the absence of PMCA2 has a greater effect on scotopic than photopic responses.

\section{Discussion}

PMCA isoform 2, a $\mathrm{Ca}^{2+}$ transporter with high affinity for $\mathrm{Ca}^{2+}$, is strongly expressed in all vertebrate retinas (Križaj et al., 2002, 2004; Rentería et al., 2005). This study shows that amplitude and timing of scotopic light-evoked responses is compromised in deafwaddler ${ }^{2 J}$ $\left(d f w^{2 J}\right)$ mouse retinas that lack PMCA2. In contrast, the photopic cone-dominated pathway was relatively unaffected. These results suggest that high-affinity $\mathrm{Ca}^{2+}$ extrusion modulates transmission of light-evoked responses in the scotopic visual pathway to a much greater extent than the photopic pathway.

\section{The role of PMCA2 in photoreceptor signaling}

Photoreceptors in $d f w^{2 J}$ mice were anatomically indistinguishable from those of their littermate controls. The thickness of the outer and inner nuclear layers and the length of rod outer segments in $d f w^{2 J}$ mice and controls were nearly identical. Direct recordings from isolated rod outer segments revealed that sensitivity and kinetics of light responses in $d f w^{2 J}$ animals were normal. This result was consistent with absence of PMCA2 immunoreactivity from $d f w^{2 J}$ outer segments and suggested that PMCA2 does not regulate photoreceptor development or phototransduction.

As opposed to the recordings from single cells, the amplitude of the scotopic a-wave, generally taken to represent integrated light-evoked activity of rods, was reduced by $\sim 25 \%$ in $d f w^{2 J}$ retinas. A similar effect was reported by Jiang et al. (1996), who found that a-wave amplitudes in PLC $\beta 4$ knock-out mice were decreased with no change in the number of rods, rod outer segment length, or photoresponses of individual rods. At least four mechanisms could contribute to the reduction of the a-wave in retinas with normal rod photoresponses. (1) Trivially, the decrease in the a-wave amplitude in $d f w^{2 J}$ s could be attributable to an increase in extracellular conductivity in $d f w^{2 J}$ retinas. This mechanism would predict an equivalent decrease in the amplitude of photopic b-waves in $d f w^{2 J}$ animals, which was not observed. (2) A-waves could have decreased because of intervention of an attenuating filter provided by a cataractous lens. However, rodent lens expresses only PMCA1 (Nabekura et al., 2001), and
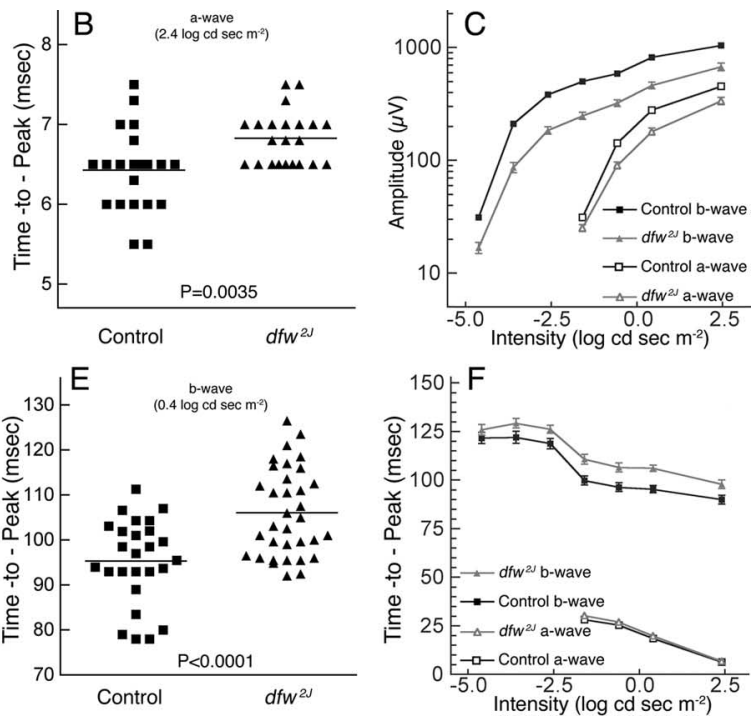

Figure 7. Scotopic a-wave amplitudes elicited by $2.4 \log \mathrm{cd} \mathrm{s} \mathrm{m}^{-2}$ flashes are significantly lower $(\boldsymbol{A})$ and time-to-peak is slower $(\boldsymbol{B})$ in $\mathrm{dfw}^{2 J}$ (triangles) than in control (squares) mice. $\boldsymbol{C}$, Scotopic a- and b-wave amplitudes are significantly reduced at ses: $p<0.000001$ for scotopicb-waves at allintensities shown) Scotopicb-wave amplitudes are also significantly lower (D) and time-to-peak is slower $(\boldsymbol{E})$ in $d f w^{2 J}$ (triangles) than in control (squares) mice. The ERG data shown in $\boldsymbol{D}$ and $\boldsymbol{E}$ are responses to . $10 \mathrm{~g} \mathrm{~cd} \mathrm{~s} \mathrm{~m}^{-2}$ white stimulus, corresponding to $1256 \mathrm{Rh}^{*}$. Mean values are shown as horizontal lines. $\boldsymbol{F}$, Scotopic b-wave increments among $d f w^{2 J}$ compared with control mice ( $p<0.001$ for scotopic b-waves at all intensities shown; $p=0.02$ for

A.

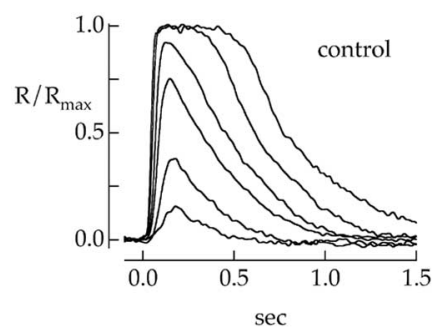

C.

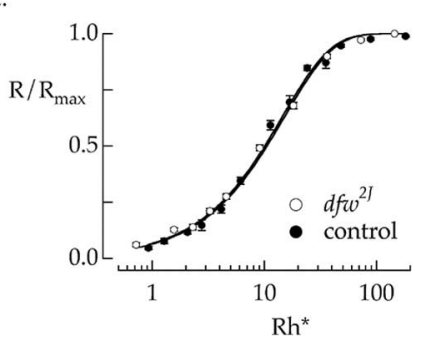

B.

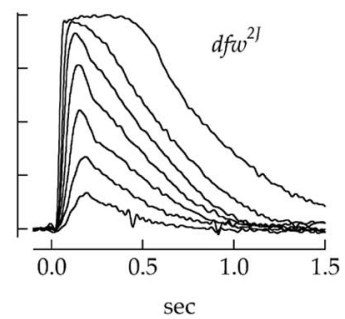

D.

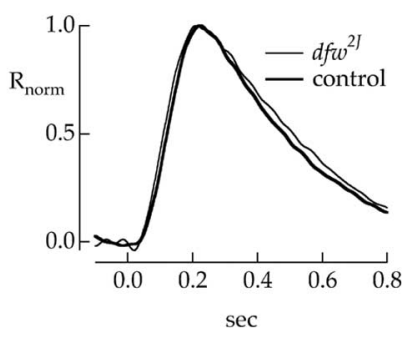

Figure 8. Outer segment membrane currents are unaltered by lack of PMCA2.A, Flash family for a single control rod. Each trace is an average of 10 responses. Flashes produced between 2 and $140 \mathrm{Rh}^{*} / \mathrm{rod}$. B, Flash family for a single mutant $d f w^{2 J}$ rod. C, Stimulus-response relationship from 22 control and $25 \mathrm{dfw} w^{2\lrcorner}$ rods. Data have been fit with a saturating exponential function. $\boldsymbol{D}$, Normalized dim flash responses. Responses to flashes producing $0.5-4 \mathrm{Rh}^{*}$ were averaged across control and $d f w^{2 J}$ rods. To compare kinetics, the resulting average responses were normalized. All flashes were $10 \mathrm{~ms}$ and delivered at $t=0$. Bandwidth is $30 \mathrm{~Hz}$.

no cataracts were observed during external examination of $d f w^{2 J}$ eyes. (3) Mutant retinas could contain patches of dysfunctional rods. Although no obvious patches were identified by light microscopic analysis of $d f w^{2 J}$ retinal anatomy or by immunofluorescence, this possibility cannot be excluded. (4) PMCA2 could modulate the a-wave amplitude via posttransduction signaling pathway either in the inner segment and/or postsynaptically. 
A.

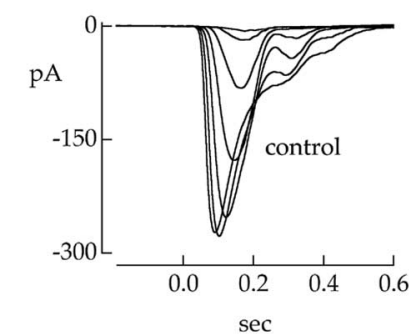

C.

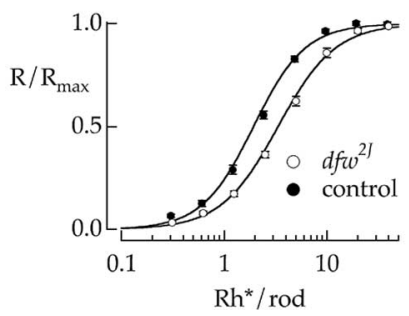

B.

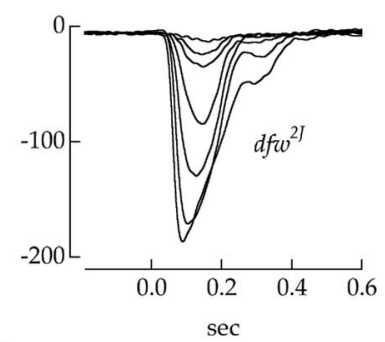

D.

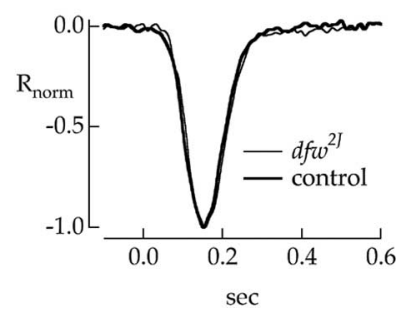

Figure 9. Rod bipolar sensitivity is compromised in the absence of PMCA2. $\boldsymbol{A}$, Flash family plotted for a single control rod bipolar cell. Each trace is an average of 25 responses. Flashes produced between 0.3 and $40 \mathrm{Rh}^{*} / \mathrm{rod}$. $\boldsymbol{B}$, Flash family for a single $d f w^{2 J}$ rod bipolar cell. $\boldsymbol{C}$, Stimulus-response relationship from 61 control and $11 \mathrm{dfw^{2J }}$ rod bipolar cells. Data were fit with a Hill curve. $\boldsymbol{D}$, Normalized dim flash responses. Responses to flashes producing $0.3-0.6$ $\mathrm{Rh}^{*}$ were averaged across control and $d f w^{2 J}$ rod bipolar cells. To compare kinetics, the resulting average responses were normalized. All flashes were $10 \mathrm{~ms}$ and delivered at $t=0$. Bandwidth is $50 \mathrm{~Hz}$.

Pharmacological manipulation of glutamate, dopamine, and GABA receptors has been shown to reduce dark-adapted a-wave amplitudes in frog, cat, rat, and primate retinas (Jaffe et al., 1985; Xu et al., 1991; Jamison et al., 2001; Szikra and Witkovsky, 2001; Möller and Eysteinsson, 2003; Robson et al., 2003), suggesting that the a-wave might have been compromised indirectly by signaling deficits in the inner segment, the inner retina, or altered feedback from postsynaptic cells. However, it is noteworthy that the a-wave in nob mice is normal despite total loss of rod bipolar cell responses (Pardue et al., 1998).

\section{PMCA2 modulates synaptic transmission at rod synapses}

Loss of PMCA2 alters signaling from rods to rod bipolar cells. Recordings from individual $d f w^{2 J}$ rod bipolar cells showed that the sensitivity of light-evoked synaptic transmission was reduced by $\sim 50 \%$, consistent with the reduction in the amplitude of the scotopic b-wave in $d f w^{2 J}$ animals. Decreased b-wave responses were observed at light intensities that evoked no discernible a-wave responses (Fig. 7C). This loss of sensitivity could indirectly control the timing of visual signals, as seen in the $11 \mathrm{~ms}$ increase in time-to-peak of the $d f w^{2 I}$ scotopic b-wave. On the assumption that loss of PMCA2 during development did not have an indirect effect on rod and rod bipolar synaptogenesis, our data indicate that PMCA2-mediated $\mathrm{Ca}^{2+}$ extrusion represents a post-phototransduction mechanism that increases the gain of the scotopic pathway.

PMCA2 is expressed both presynaptically in rod terminals and postsynaptically in bipolar cells. Hence, glutamate release and/or mGluR6 signaling could have been affected in $d f w^{2 J}$ retinas. Although the kinetics of exocytosis and synaptic depression appear to be similar in rods and cones (Kreft et al., 2003; Rabl et al., 2006), the neurotransmission at cone synapses is significantly faster (Schnapf and Copenhagen, 1982; Cadetti et al., 2005). This may be attributable to different mechanisms of $\left[\mathrm{Ca}^{2+}\right]_{\mathrm{i}}$ homeostasis in rods and cones (Križaj et al., 2003; Heidelberger et

al., 2005). Loss of high-affinity $\mathrm{Ca}^{2+}$ extrusion would slow kinetics of $\mathrm{Ca}^{2+}$ extrusion and glutamate release, causing an increase in synaptic delays. A non-mutually exclusive alternative mechanism would be an increase in steady-state $\left[\mathrm{Ca}^{2+}\right]_{i}$ in darkadapted rod bipolar cells attributable to $\mathrm{Ca}^{2+}$ influx through mGluR6-gated transduction channels. The transduction channels in depolarizing bipolar cells are $\mathrm{Ca}^{2+}$-permeable and desensitize in the presence of elevated $\left[\mathrm{Ca}^{2+}\right]_{\mathrm{i}}$ (Shiells and Falk, 1999; Berntson et al., 2004; Nawy, 2004). Elevated $\left[\mathrm{Ca}^{2+}\right]_{i}$ would, in turn, "adapt" rod bipolar responses to light stimulation, accounting for the loss of sensitivity observed in ERG and single-cell recordings. In preliminary experiments using BAPTA-filled rod bipolar cells depolarized to $+60 \mathrm{mV}$, we saw little change in the sensitivity of light responses (A. Sampath and F. Rieke, unpublished observations), suggesting that changes in $\left[\mathrm{Ca}^{2+}\right]_{\mathrm{i}}$ play a minor role in mouse rod bipolar function. This would suggest a more prominent role for the presynaptic component of PMCA2 action at the rod synapse. However, it is likely that the role of PMCA2 is more significant in light-adapted cells with elevated $\left[\mathrm{Ca}^{2+}\right]_{\mathrm{i}}$ (Berntson et al., 2004).

The increase in time-to-peak responses in scotopic b-waves of $d f w^{2 J}$ retinas was highly significant at high intensities of illumination. At light levels comparable with those used in retinal slice recordings b-wave delays were reduced to $\sim 5 \mathrm{~ms}$, which is within the SE of kinetic measurements in rod bipolar cell recordings. Consequently, the kinetics of rod bipolar responses in $d f w^{2 J}$ retinas was not significantly different from the controls.

In contrast to scotopic responses, no statistically significant effect on the amplitude and kinetics of light-evoked responses was observed in the cone-dominated pathway. Cones do not express PMCA2, suggesting the cone pathway is dominated by the less sensitive PMCA1 mechanism (Križaj et al., 2002; Haverkamp et al., 2003). A subset of GFP-negative INL cells in retinas from L7-GFP transgenic mice was immunoreactive for PMCA2, indicating that PMCA2 could be localized to cone bipolar cells (Tomomura et al., 2001). However, our observation that photopic ERG is unaffected in PMCA2-deficient mice, together with lack of PMCA2 expression in cones, suggests that this isoform does not play a major role in the cone pathway. This is the first report of PMCA expression in retinal glia. At the moment, it is not known what role PMCAs play in Müller cell function or whether glial processes regulate rod or cone neurotransmission.

\section{PMCA2 plays a different role in synaptogenesis of visual and auditory tissues}

Cell populations in the mammalian retina express specific PMCA isoforms at defined developmental stages (Križaj et al., 2002; Rentería et al., 2005). PMCA2 was expressed throughout the early postnatal mouse retina, including the neuroblast precursors of photoreceptor cells. However, unlike the pronounced cellular degeneration observed in the cochlea, vestibular, and cerebellar structures of PMCA2-deficient mice (Street et al., 1998; Kozel et al., 1998, 2002; Dodson and Charabalapoulou, 2001), no obvious morphological phenotype was observed in adult $d f w^{2 J}$ retinas up to 2 years of age. Moreover, a qualitative analysis revealed no correlation between the eye size and ERG potentials in $d f w^{2 J}$ mice. These results suggest that upregulated activation of other $\mathrm{Ca}^{2+}$ extrusion and/or intracellular sequestration mechanisms may be able to compensate for the absence of PMCA2 during development of the retina and the eye. Because the loss of the retinal PMCA2 gene is functionally selective and does not lead to detectable changes in mRNA levels of other three PMCA isoforms (Fig. 2 ), it is likely that visual deficits observed in $d f w^{2 J}$ mice occur as a 

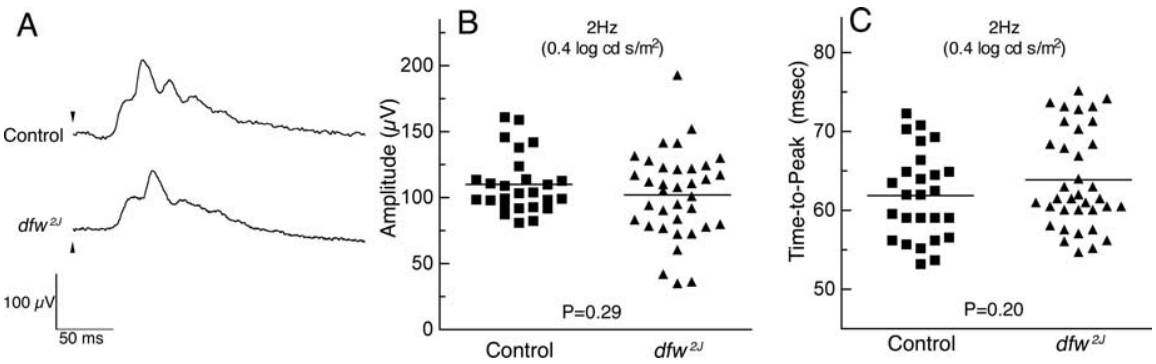

Figure 10. $\quad \boldsymbol{A}$, Representative photopic ERG waveforms from control (top trace) and $d f w^{2 J}$ (bottom trace) mice in response to a $2 \mathrm{~Hz}$ stimulus. The $d f w^{2 J}$ recordings (triangles) are similar in amplitude $(\boldsymbol{B})$ and timing $(\boldsymbol{C})$ to control responses (squares). Mean values are shown as horizontal lines.

result of loss of specific regulatory properties of PMCA2 and not secondary effects attributable to abnormalities in number or type of retinal neurons or compensatory expression of PMCA1, PMCA3, or PMCA4 genes.

Our results suggest that catalytic and/or modulatory properties of PMCA2 are relevant for regulating the sensitivity and kinetics of light responses in retinal pathways. PMCA1, the isoform mainly expressed in ribbon-containing cells (Križaj et al., 2002), is by far the most abundant retinal PMCA isoform (Fig. 2), required for the "housekeeping" $\mathrm{Ca}^{2+}$ clearance in tonically depolarized photoreceptors and cone bipolar cells. PMCA2 is likely to dominate $\mathrm{Ca}^{2+}$ clearance in amacrine and ganglion cells, as well as to increase the sensitivity of signaling in rods and rod bipolar cells. Although we did not directly measure function in inner retinal neurons from $d f w^{2 I}$ animals, the elevated STR threshold responses suggest that activation of amacrine cells and/or ganglion cells is also compromised in $d f w^{2 J}$ retinas.

In conclusion, we quantified the expression of all four PMCA isoforms in the mouse retina, characterized the expression of PMCA2 during development, and determined its functional role in modulating light-evoked signaling in retinal circuits and visual cortex. Our results suggest that high-affinity $\mathrm{Ca}^{2+}$ extrusion uniquely provided by PMCA2 modulates the rod-cone balance by selectively increasing the dynamic range and timing of rod synapses.

\section{References}

Armstrong-Gold CE, Rieke F (2003) Bandpass filtering at the rod to secondorder cell synapse in salamander (Ambystoma tigrinum) retina. J Neurosci 23:3796-3806.

Barrett EF, Stevens CF (1972) The kinetics of transmitter release at the frog neuromuscular junction. J Physiol (Lond) 227:691-708.

Bayer AU, Mittag T, Cook P, Brodie SE, Podos SM, Maag KP (1999) Comparisons of the amplitude size and the reproducibility of three different electrodes to record the corneal flash electroretinogram in rodents. Doc Ophthalmol 98:233-246.

Baylor DA, Lamb TD, Yau KW (1979) The membrane current of single rod outer segments. J Physiol (Lond) 288:589-611.

Berntson A, Smith RG, Taylor WR (2004) Postsynaptic calcium feedback between rods and rod bipolar cells in the mouse retina. Vis Neurosci 21:913-924.

Berridge MJ, Bootman MD, Roderick HL (2003) Calcium signalling: dynamics, homeostasis and remodelling. Nat Rev Mol Cell Biol 4:517-529.

Blaustein MP, Goldman WF, Fontana G, Krueger BK, Santiago EM, Steele TD, Weiss DN, Yarowsky PJ (1991) Physiological roles of the sodiumcalcium exchanger in nerve and muscle. Ann NY Acad Sci 639:254-274.

Bok D, Yasumura D, Matthes MT, Ruiz A, Duncan JL, Chappelow AV, Zolutukhin S, Hauswirth W, LaVail MM (2002) Effects of adenoassociated virus-vectored ciliary neurotrophic factor on retinal structure and function in mice with a P216L rds/peripherin mutation. Exp Eye Res 74:719-735.

Brini M, Coletto L, Pierobon N, Kraev N, Guerini D, Carafoli E (2003) A comparative functional analysis of plasma membrane $\mathrm{Ca}^{2+}$ pump isoforms in intact cells. J Biol Chem 278:24500-24508.

Burette A, Rockwood JM, Strehler EE, Weinberg RJ (2003) Isoform-specific distribution of the plasma membrane $\mathrm{Ca}^{2+}$ ATPase in the rat brain. J Comp Neurol 467:464-476.

Cadetti L, Tranchina D, Thoreson WB (2005) A comparison of release kinetics and glutamate receptor properties in shaping rod-cone differences in EPSC kinetics in the salamander retina. J Physiol 569:773-778.

Caride AJ, Filoteo AG, Penheiter AR, Paszty K, Enyedi A, Penniston JT (2001) Delayed activation of the plasma membrane calcium pump by a sudden increase in $\mathrm{Ca}^{2+}$ : fast pumps reside in fast cells. Cell Calcium 30:49-57.

Dodson HC, Charalabapoulou M (2001) PMCA2 mutation causes structural changes in the auditory system in deafwaddler mice. J Neurocytol 30:281-292.

Dumont RA, Lins U, Filoteo AG, Penniston JT, Kachar B, Gillespie PG (2001) Plasma membrane $\mathrm{Ca}^{2+}$-ATPase isoform 2a is the PMCA of hair bundles. J Neurosci 21:5066-5078.

Duncan JL, LaVail MM, Yasumura D, Matthes MT, Yang H, Trautmann N, Chappelow AV, Feng W, Earp HS, Matsushima GK, Vollrath D (2003) An RCS-like retinal dystrophy phenotype in mer knockout mice. Invest Ophthalmol Vis Sci 44:826-838.

El-Amraoui A, Petit C (2005) Usher I syndrome: unravelling the mechanisms that underlie the cohesion of the growing hair bundle in inner ear sensory cells. J Cell Sci 118:4593-4603.

Felmy F, Neher E, Schneggenburger R (2003) The timing of phasic transmitter release is $\mathrm{Ca}^{2+}$-dependent and lacks a direct influence of presynaptic membrane potential. Proc Natl Acad Sci USA 100:15200-15205.

Field GD, Rieke F (2002) Mechanisms regulating variability of the single photon responses of mammalian rod photoreceptors. Neuron 15:733747.

Filoteo AG, Elwess NL, Enyedi A, Caride A, Aung HH, Penniston JT (1997) Plasma membrane $\mathrm{Ca}^{2+}$ pump in rat brain. Patterns of alternative splices seen by isoform-specific antibodies. J Biol Chem 272:23741-23747.

Granit R (1947) Sensory mechanisms of the retina. London: Oxford UP.

Green DG, Kapousta-Bruneau NV (1999) A dissection of the electroretinogram from the isolated rat retina with microelectrodes and drugs. Vis Neurosci 16:727-741.

Guerini D, Garcia-Martin E, Gerber A, Volbracht C, Leist M, Merino CG, Carafoli E (1999) The expression of plasma membrane $\mathrm{Ca}^{2+}$ pump isoforms in cerebellar granule neurons is modulated by $\mathrm{Ca}^{2+}$. J Biol Chem 274:1667-1676.

Haverkamp S, Ghosh KK, Hirano AA, Wassle H (2003) Immunocytochemical description of five bipolar cell types of the mouse retina. J Comp Neurol 455:463-476.

Heidelberger R, Thoreson WB, Witkovsky P (2005) Synaptic transmission at retinal ribbon synapses. Prog Retin Eye Res 24:682-720.

Hetling JR, Pepperberg DR (1999) Sensitivity and kinetics of mouse rod flash responses determined in vivo from paired-flash electroretinograms. J Physiol (Lond) 516:593-609.

Hilfiker H, Guerini D, Carafoli E (1994) Cloning and expression of isoform 2 of the human plasma membrane $\mathrm{Ca}^{2+}$ ATPase. Functional properties of the enzyme and its splicing products. J Biol Chem 269:26178-26183.

Jaffe M, Levinson P, de Monasterio F, Adams B (1985) Effects of a dopaminergic antagonist on the Ganzfeld ERG of humans. Proc Invest Ophthalmol Vis Sci 26:61.

Jamison JA, Bush RA, Lei B, Sieving PA (2001) Characterization of the rod photoresponse isolated from the dark-adapted primate ERG. Vis Neurosci 18:445-455.

Jiang H, Lyubarsky A, Dodd R, Vardi N, Pugh E, Baylor D, Simon MI, Wu D (1996) Phospholipase C beta 4 is involved in modulating the visual response in mice. Proc Natl Acad Sci USA 93:14598-14601.

Konrad-Martin D, Norton SJ, Mascher KE, Tempel BL (2001) Effects of PMCA2 mutation on DPOAE amplitudes and latencies in deafwaddler mice. Hear Res 151:205-220.

Kozel PJ, Friedman RA, Erway LC, Yamoah EN, Liu LH, Riddle T, Duffy JJ, 
Doetschman T, Miller ML, Cardell EL, Shull GE (1998) Balance and hearing deficits in mice with a null mutation in the gene encoding plasma membrane $\mathrm{Ca}^{2+}$-ATPase isoform 2. J Biol Chem 273:18693-18696.

Kozel PJ, Davis RR, Krieg EF, Shull GE, Erway LC (2002) Deficiency in plasma membrane calcium ATPase isoform 2 increases susceptibility to noise-induced hearing loss in mice. Hear Res 164:231-239.

Kreft M, Križaj D, Grilc S, Zorec R (2003) Properties of exocytotic response in vertebrate photoreceptors. J Neurophysiol 90:218-225.

Križaj D, Copenhagen DR (1998) Compartmentalization of calcium extrusion mechanisms in the outer and inner segments of photoreceptors. Neuron 21:249-256.

Križaj D, Demarco SJ, Johnson J, Strehler EE, Copenhagen DR (2002) Cellspecific expression of plasma membrane calcium ATPase isoforms in retinal neurons. J Comp Neurol 451:1-21.

Križaj D, Lai FA, Copenhagen DR (2003) Ryanodine stores and calcium regulation in the inner segments of salamander rods and cones. J Physiol (Lond) 547:761-774.

Križaj D, Liu X, Copenhagen DR (2004) Expression of calcium transporters in the retina of the tiger salamander (Ambystoma tigrinum). J Comp Neurol 475:463-480.

LaVail MM, Battelle BA (1975) Influence of eye pigmentation and light deprivation on inherited retinal dystrophy in the rat. Exp Eye Res 21:167-192.

Lyubarsky AL, Pugh Jr EN (1996) Recovery phase of the murine rod photoresponse reconstructed from electroretinographic recordings. J Neurosci 16:563-571.

Masu M, Iwakabe H, Tagawa Y, Miyoshi T, Yamashita M, Fukuda Y, Sasaki H, Hiroi K, Nakamura Y, Shigemoto R, Nakanishi S (1995) Specific deficit of the ON response in visual transmission by targeted disruption of the mGluR6 gene. Cell 80:757-765.

McCullough BJ, Tempel BL (2004) Haplo-insufficiency revealed in deafwaddler mice when tested for hearing loss and ataxia. Hear Res 195:90-102.

Meinrenken CJ, Borst JG, Sakmann B (2003) Local routes revisited: the space and time dependence of the $\mathrm{Ca}^{2+}$ signal for phasic transmitter release at the rat calyx of Held. J Physiol (Lond) 547:665-689.

Möller A, Eysteinsson T (2003) Modulation of the components of the rat dark-adapted electroretinogram by the three subtypes of GABA receptors. Vis Neurosci 20:535-542.

Nabekura T, Takeda M, Hori R, Tomohiro M, Ito Y (2001) Expression of plasma membrane $\mathrm{Ca}(2+)$-ATPase in lenses from normal and hereditary cataract UPL rats. Curr Eye Res 22:446-450.

Nawy S (2004) Desensitization of the mGluR6 transduction current in tiger salamander On bipolar cells. J Physiol (Lond) 558:137-146.

Newman EA (2004) Glial modulation of synaptic transmission in the retina. Glia 47:268-274.

Noben-Trauth K, Zheng QY, Johnson KR, Nishina PM (1997) dfw: a deafness susceptibility locus that interacts with deafwaddler (dfw). Genomics 44:266-272.

Pardue MT, McCall MA, LaVail MM, Gregg RG, Peachey NS (1998) A naturally occurring mouse model of X-linked congenital stationary night blindness. Invest Ophthalmol Vis Sci 39:2443-2449.

Peachey NS, Goto Y, al-Ubaidi MR, Naash MI (1993) Properties of the mouse cone-mediated electroretinogram during light adaptation. Neurosci Lett 162:9-11.

Penn RD, Hagins WA (1969) Signal transmission along retinal rods and the origin of the electroretinographic a-wave. Nature 223:201-204.

Pennesi ME, Lyubarsky AL, Pugh Jr EN (1998) Extreme responsiveness of the pupil of the dark-adapted mouse to steady retinal illumination. Invest Ophthalmol Vis Sci 39:2148-2156.

Rabl K, Cadetti L, Thoreson WB (2006) Paired-pulse depression at photoreceptor synapses. J Neurosci 26:2555-2563.

Rentería RC, Strehler EE, Copenhagen DR, Križaj D (2005) Ontogeny of plasma membrane calcium ATPase isoforms in the neural retina of the postnatal rat. Vis Neurosci 22:263-274.

Rich KA, Figueroa SL, Zhan Y, Blanks JC (1995) Effects of Muller cell disruption on mouse photoreceptor cell development. Exp Eye Res 61:235-248.

Robson JG, Frishman LJ (1995) Response linearity and kinetics of the cat retina: the bipolar cell component of the dark-adapted electroretinogram. Vis Neurosci 12:837-850.

Robson JG, Saszik SM, Ahmed J, Frishman LJ (2003) Rod and cone contri- butions to the a-wave of the electroretinogram of the macaque. J Physiol (Lond) 547:509-530.

Rozen S, Skaletsky H (2000) Primer3 on the WWW for general users and for biologist programmers. Methods Mol Biol 132:365-386.

Sarantis M, Mobbs P (1992) The spatial relationship between Muller cell processes and the photoreceptor output synapse. Brain Res 584:299-304.

Saszik SM, Robson JG, Frishman LJ (2002) The scotopic threshold response of the dark-adapted electroretinogram of the mouse. J Physiol 543:899916.

Schnapf JL, Copenhagen DR (1982) Differences in the kinetics of rod and cone synaptic transmission. Nature 296:862-864.

Shiells RA, Falk G (1999) A rise in intracellular $\mathrm{Ca}^{2+}$ underlies light adaptation in dogfish retinal "on" bipolar cells. J Physiol (Lond) 514:343-350.

Shull GE (2000) Gene knockout studies of $\mathrm{Ca}^{2+}$-transporting ATPases. Eur J Biochem 267:5284-5290.

Sieving PA, Nino C (1988) Scotopic threshold response (STR) of the human electroretinogram. Invest Ophthalmol Vis Sci 29:1608-1614.

Silverstein RS, Tempel BL (2006) Atp2b2, encoding $\mathrm{Ca}^{2+}$-atpase type 2, exhibits tissue-specific first exon usage in hair cells, neurons, and mammary glands of mice. Neuroscience, in press.

Stahl WL, Eakin TJ, Owens Jr JW, Breininger JF, Filuk PE, Anderson WR (1992) Plasma membrane $\mathrm{Ca}^{2+}$-ATPase isoforms: distribution of mRNAs in rat brain by in situ hybridization. Brain Res Mol Brain Res 16:223-231.

Stauffer TP, Guerini D, Carafoli E (1995) Tissue distribution of the four gene products of the plasma membrane $\mathrm{Ca}^{2+}$ pump. A study using specific antibodies. J Biol Chem 270:12184-12190.

Street VA, McKee-Johnson JW, Fonseca RC, Tempel BL, Noben-Trauth K (1998) Mutations in a plasma membrane $\mathrm{Ca}^{2+}$-ATPase gene cause deafness in deafwaddler mice. Nat Genet 19:390-394.

Strehler EE, Zacharias DA (2001) Role of alternative splicing in generating isoform diversity among plasma membrane calcium pumps. Physiol Rev 81:21-50.

Szikra T, Witkovsky P (2001) Contributions of AMPA- and kainatesensitive receptors to the photopic electroretinogram of the Xenopus retina. Vis Neurosci 18:187-196.

Takahashi K, Kitamura K (1999) A point mutation in a plasma membrane $\mathrm{Ca}^{(2+)}$-ATPase gene causes deafness in Wriggle Mouse Sagami. Biochem Biophys Res Commun 261:773-778.

Tank DW, Regehr WG, Delaney KR (1995) A quantitative analysis of presynaptic calcium dynamics that contribute to short-term enhancement. J Neurosci 15:7940-7952.

Tomomura M, Rice DS, Moran JI, Yuzaki M (2001) Purification of Purkinje cells by fluorescence-activated cell sorting from transgenic mice that express green fluorescent protein. Eur J Neurosci 14:57-63.

Vandesompele J, De Preter K, Pattyn F, Poppe B, Van Roy N, De Paepe A, Speleman F (2002) Accurate normalization of real-time quantitative RT-PCR data by geometric averaging of multiple internal control genes. Genome Biol 3:RESEARCH0034.

Wanaverbecq N, Marsh SJ, Al-Qatari M, Brown DA (2003) The plasma membrane calcium-ATPase as a major mechanism for intracellular calcium regulation in neurones from the rat superior cervical ganglion. J Physiol (Lond) 550:83-101.

Weil D, Blanchard S, Kaplan J, Guilford P, Gibson F, Walsh J, Mburu P, Varela A, Levilliers J, Weston MD, et al. (1995) Defective myosin VIIA gene responsible for Usher syndrome type 1B. Nature 374:60-61.

Wood JD, Muchinsky SJ, Filoteo AG, Penniston JT, Tempel BL (2004) Low endolymph calcium concentrations in deafwaddler2J mice suggest that PMCA2 contributes to endolymph calcium maintenance. J Assoc Res Otolaryngol 5:99-110.

Xu XJ, Xu J, Huang B, Livsey CT, Karwoski CJ (1991) Comparison of pharmacological agents (aspartate vs. aminophosphonobutyric plus kynurenic acids) to block synaptic transmission from retinal photoreceptors in frog. Exp Eye Res 52:691-698.

Zenisek D, Davila V, Wan L, Almers W (2003) Imaging calcium entry sites and ribbon structures in two presynaptic cells. J Neurosci 23:2538-2548.

Zhong N, Beaumont V, Zucker RS (2001) Roles for mitochondrial and reverse mode $\mathrm{Na}^{+} / \mathrm{Ca}^{2+}$ exchange and the plasmalemma Ca ${ }^{2+}$ ATPase in post-tetanic potentiation at crayfish neuromuscular junctions. J Neurosci 21:9598-9607. 